\title{
Sources and sinks of larval settlement in Jasus edwardsii around New Zealand: Where do larvae come from and where do they go?
}

\author{
Stephen M. Chiswell* ${ }^{*}$ John D. Booth \\ National Institute of Water and Atmospheric Research, PO Box 14-901, Wellington, New Zealand
}

\begin{abstract}
Isolated adult populations tend to be interconnected via the larval stage. New Zealand red rock lobster Jasus edwardsii larvae metamorphose 12 to 24 mo after hatching. Because of this long larval life, J. edwardsii provides a useful species for studying population connectivity using satellite-derived ocean currents. In this study, tracks of $J$. edwardsii larvae originating from different populations are simulated to build a statistical picture of larval dispersal. By adding an algorithm for larval metamorphosis, and tuning the algorithm parameters to fit observed post-metamorphosis settlement patterns, we estimate where settlement in each population originated (i.e. larval sources), and also where larvae from each population settle (i.e. larval sinks). There are likely to be 4 major geographical areas for larval dispersal around New Zealand. In the far north, both sources and sinks are non-local. Along the east coast of the North Island, because of entrainment by the Wairarapa Eddy, sources are both local and distant, whereas most sinks are local. In contrast, to the south of the South Island, most sources are local, whereas sinks are both local and distant. The Chatham Islands form a separate geographical area, with primarily non-local sources and local sinks. The results are robust to differences in the physical model, but sensitive to metamorphosis algorithm parameters. This indicates that understanding larval behaviour is the most critical aspect in determining larval connectivity.
\end{abstract}

KEY WORDS: Jasus edwardsii $\cdot$ Lobster $\cdot$ Larval dispersal $\cdot$ Numerical modelling $\cdot$ New Zealand · Phyllosoma $\cdot$ Settlement

\section{INTRODUCTION}

Many, if not most, benthic organisms have a larval phase that leads to widespread dispersal. Thus, isolated adult populations tend to be interconnected via the larval stage, and this connectivity has many ecological implications. For example, localised stresses, such as fishing or predation by invasive species, may lead to lower recruitment at a considerable distance from the local stress. With the advent of numerical models and satellite observations of sea level, it is now practical to model oceanic dispersion of larvae, and one can begin to address the issues related to population connectivity. Here, we use satellite measurements of sea level (and hence currents) to model connectivity related to the New Zealand red rock lobster.
The New Zealand red rock lobster Jasus edwardsii (Palinuridae) supports one of New Zealand's most valuable fisheries, with annual landings of about $2500 \mathrm{t}$ (Annala et al. 2001). J. edwardsii is found around the entire mainland New Zealand coast. However, the largest adult populations are found along the east coast of the North Island, along the southwest and south coasts of the South Island, and around Stewart and Chatham Islands (Fig. 1). J. edwardsii also occurs in southern and southeastern Australia. The New Zealand fishery is managed in 10 quota management areas (Fig. 1). These management areas, known as CRA 1 to CRA 10 (CRA being short for crayfish) are not rooted in the biology.

At 12 to 24 mo, Jasus edwardsii may well have the longest larval stage of any rock lobster (Booth 1994), 


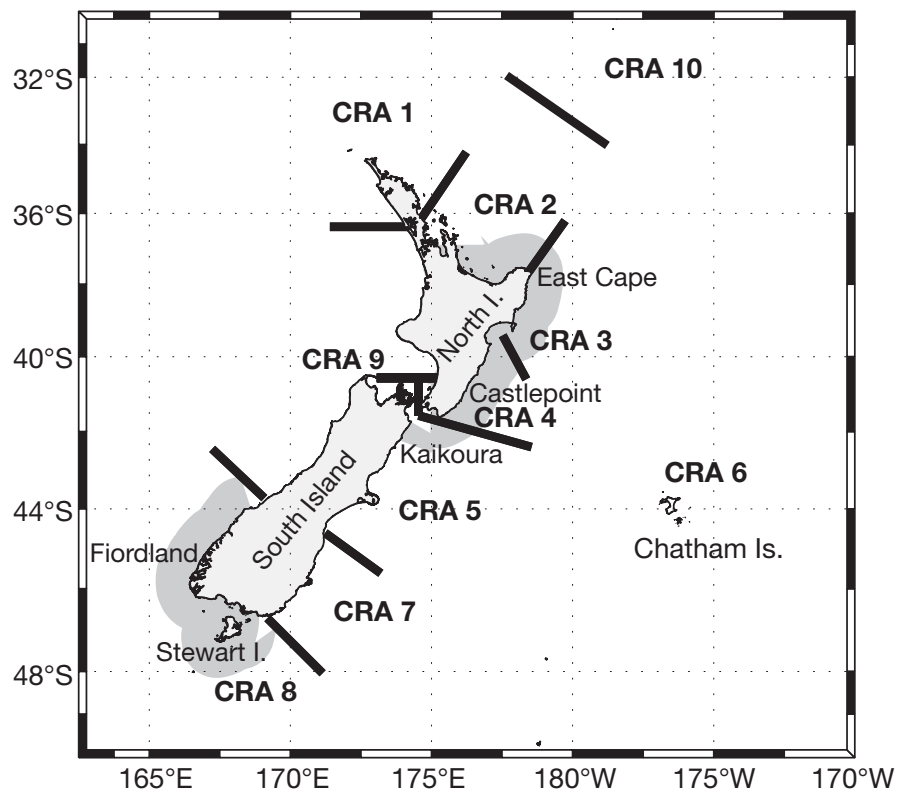

Fig. 1. New Zealand with main Jasus edwardsii fishing areas (shaded) and quota management areas (CRA 1 to 10)

and perhaps of any benthic organism (Bradbury \& Snelgrove 2001). Rock lobster larvae are known as phyllosomas (from the Greek phullon, meaning 'leaf,' and soma, meaning 'body') due to their transparent leaf-like morphology. Phyllosomas metamorphose into post-larval pueruli, which then swim shoreward to settle in the coastal zone. Pueruli have poorly developed mouth parts (Nishida et al. 1990) and apparently rely almost entirely on stored energy for their migration shoreward, implying a limit to the distance they can migrate.

Because of the long larval life and limited swimming range of the pueruli, there must be some mechanism that keeps phyllosomas close enough to the coast (or brings them back) to allow them to metamorphose and then recruit successfully. Off the east coast of the North Island, phyllosomas get entrained in the Wairarapa Eddy, a semi-permanent anticyclonic eddy (Roemmich \& Sutton 1998); this leads to the high levels of puerulus settlement observed south of East Cape (Booth 1994, 2002, Chiswell \& Roemmich 1998). In contrast, there has been no definitive explanation of any entrainment mechanism that leads to the high settlement seen in the southwest of the South Island (part of CRA 8). It has been suggested that phyllosomas can be carried across the Tasman Sea within their lifetime and that Australian stocks may in part support the South Island fishery (Chiswell et al. 2003). This idea is supported by the fact that it has not been possible to distinguish genetically lobsters between New Zealand and Australia (Ovenden et al. 1992).
Also, because of the length of the phyllosoma stage, metamorphosis - and hence settlement of the pueruli-may take place long distances from where the phyllosomas originated. Thus, some Jasus edwardsii populations may be supported, either fully or partially, by spawning at distant locations. In addition, phyllosomas derived from some regions may be more likely entrained into an eddy system (or systems) than those originating elsewhere, so the relative importance in maintaining the overall rock lobster population may differ markedly between regions. The fisheries management implications of these spatial patterns in larval dispersal are clear: adult populations that make relatively high contribution to larval recruitment may need to be managed differently from those that do not, and possible larval interconnections between regions may mean that it is not optimal to manage quota management areas independently of each other.

The aim of this article is to illustrate modelling techniques used to address the connectivity of Jasus edwardsii populations. With the advent of satellitemeasured ocean currents one can numerically model tracks of individual phyllosomas originating from different locations. By making many such simulations, each starting at a different time, one can build a statistical picture of both where larvae from a particular source settle (i.e. larval sinks), and conversely, where settlement at a particular location originated from (i.e. sources of settlement). Results are presented in terms of the Jasus edwardsii quota management areas; we estimate both the sources of settlement and larval sinks for each quota management area.

\section{METHODS}

Currents around New Zealand. New Zealand is located in the predominantly eastward-flowing southern arm of the South Pacific Gyre, which in the north of the region can be seen as the Tasman Front running zonally across the Tasman Sea (Fig. 2). This extension of the western boundary current attaches to the New Zealand landmass and flows southeast down the east coast of the North Island, where it is known as the East Auckland Current north of East Cape, and the East Cape Current south of East Cape (e.g. Heath 1985). To the south, the Subtropical Front flows across the Tasman Sea as a relatively broad and weak current at about the latitude of Fiordland. The Subtropical Front attaches to the east coast of the South Island, where it becomes relatively narrow and strong, and is known as the Southland Current. The Southland Current flows northeast to about $43^{\circ} \mathrm{S}$, where part of it flows northwards and contributes to the Wairarapa Coastal Current flowing north along the east coast of the North 


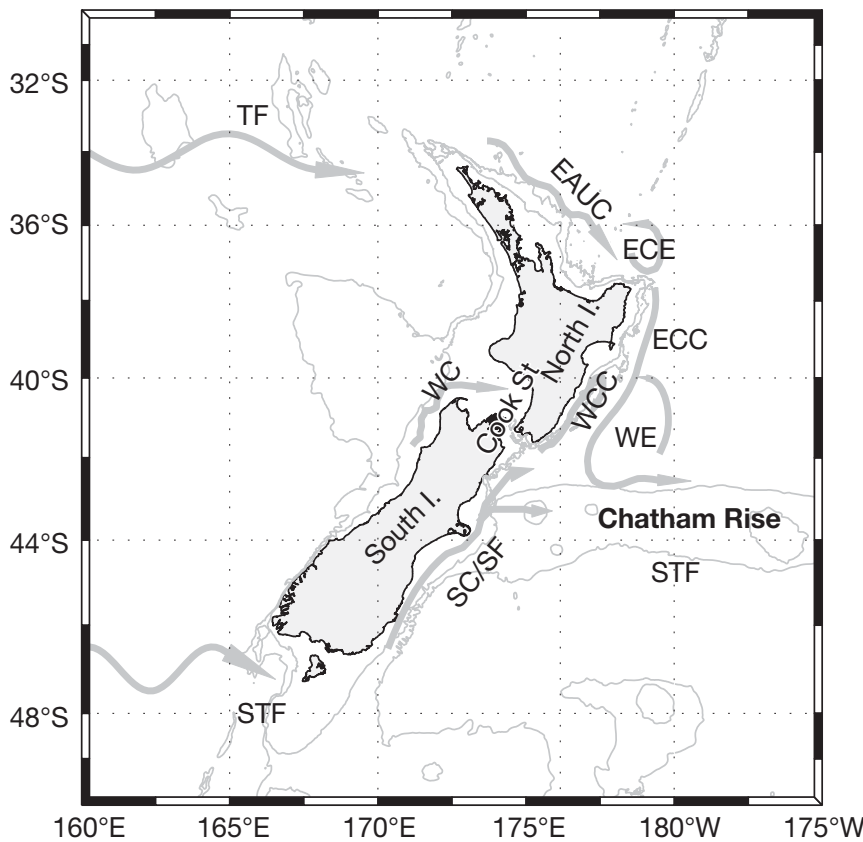

Fig. 2. Major currents around New Zealand: the Tasman Front (TF), East Auckland Current (EAUC), East Cape Current (ECC), Southland Current/Front (SC/SF) and Westland Current (WC). Semi-permanent eddies embedded in the flow are the Wairarapa Eddy (WE) and East Cape Eddy (ECE)

Island. The remainder peels away from the coast as the continuation of the Subtropical Front to flow eastwards along the Chatham Rise (Chiswell 2000). There are several 'semi-permanent' eddies embedded in the mean flow, and these eddies are the basis of the recirculation that entrains phyllosomas. The main eddies east of the North Island are the East Cape and Wairarapa Eddies, and the smaller and apparently more transitory Hikurangi Eddy (Roemmich \& Sutton 1998, Chiswell 2005); the Hikurangi Eddy is not shown in Fig. 2. There could also be permanent eddies in the flow around the South Island, but because there have been relatively few observations of the circulation in this region, the presence of any such eddies has not been documented.

Lifecycle and biological indices. Larval production. Jasus edwardsii breeds annually. Egg hatching takes place in spring (September to November), starting and finishing about a month earlier in the north than in the south (MacDiarmid 1989). The eggs hatch into the short-lived (about 30 min duration) naupliosoma larvae before moulting into Stage 1 phyllosomas. The naupliosoma stage is so transient that it is no longer considered here. For simplicity, we refer to phyllosomas 'hatching,' although strictly speaking, it is the naupliosoma that hatches. There are 11 phyllosoma stages (Lesser 1978), comprising about 17 instars (Kittaka et al. 2005). Whereas Stage 1 phyllosomas are found inshore, by Stage 5 all surviving larvae are well offshore in oceanic waters.

Larval production per unit length of coastline varies according to the abundance of mature females and fecundity, which in turn is dependent on size and age at maturity. Because fecundity of similar-sized females varies little geographically (Annala \& Bycroft 1987), larval production is principally determined by the biomass of mature females. Estimates of the biomass of mature females for various quota management areas and sub stocks are available from stock assessment models (P. Breen, NIWA, pers. comm.), and these provide an index of larval production for each quota management area. Here, the estimated biomass of mature females was divided by the length of coastline (excluding estuaries and harbours and all but the largest islands) to give an index of annual larval production per unit length of coastline (Fig. 3).

Metamorphosis and settlement. After metamorphosis, pueruli swim towards land and eventually settle in the coastal zone. How pueruli navigate is a subject of some debate: they may swim towards sound generated by ocean wave activity in the coastal zone (Phillips \& Macmillan 1987), but there may be some other navigational cue (Bradford et al. 2005, Jeffs et al. 2005). Jeffs et al. (2001) calculated that the non-feeding puerulus

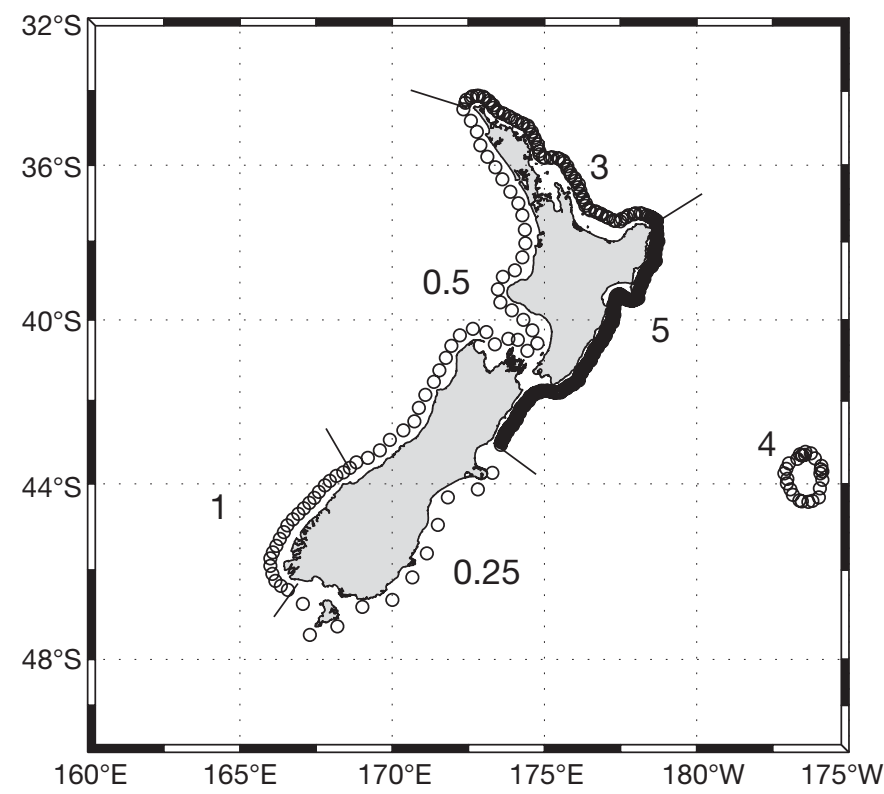

Fig. 3. Jasus edwardsii. Annual larval production per unit length coastline (numbers), derived from spawning biomass estimates from stock assessment, assuming uniform fecundity per female (P. Breen pers. comm.). The index has been normalised so that production per unit length coastline for Fiordland fishery is 1 . Circles show larval source locations for the model. There were 382 hatching locations, distributed according to the larval production per unit length of coastline and placed approximately $20 \mathrm{~km}$ from shore 
has the energy to swim on average $200 \mathrm{~km}$ for the sum of both horizontal and vertical movement. Since some of the available energy is used in vertical swimming, metamorphosis must take place closer inshore than $200 \mathrm{~km}$ if the pueruli are to successfully settle.

The body of historical data suggests that metamorphosis mostly takes place closer to the coast than $200 \mathrm{~km}$. Most of the many hundreds of pueruli caught in plankton sampling have been taken in the region of the slope, within $40 \mathrm{~km}$ of the shore (Booth \& Phillips 1994). Similar results have been reported for other shallow-water palinurid species such as Jasus lalandii and Panulirus cygnus (Kanciruk 1980, Phillips 1981). However, pueruli taken with plankton sampling are actively swimming towards the coast, and it is difficult to estimate how far the pueruli have swum before being caught, but we presume that newly metamorphosed pueruli will be at the outer edges of the observed puerulus distribution. For example, in February 1998 off the east coast of the North Island, pueruli judged to be newly metamorphosed (because they had soft carapaces) had a mean distance offshore of $93 \mathrm{~km}$, compared to $71 \mathrm{~km}$ for all pueruli taken during that cruise (Chiswell \& Booth 2005).

The timing of metamorphosis is better understood. Because the non-feeding puerulus stage is estimated to exist at sea for only a matter of days or a very few weeks (authors' unpubl. data), the timing of puerulus settlement essentially reflects the timing of metamorphosis. Monthly levels of puerulus settlement have been followed for up to $25 \mathrm{yr}$ at many sites within the main rock lobster fishery areas (Booth 1994, Booth et al. 2004, Booth unpubl. data). In most parts of the country the main settlement season is winter, but along the east coast of central New Zealand, from about Castlepoint to Kaikoura, it starts as early as December (Booth 1994). Puerulus settlement computed as an average of all collector sites around the country has a peak in June and a minimum in October (Fig. 4A). We presume the minimum in October corresponds to the change from one cohort to the next.

Settlement also varies spatially around the country. Altogether there were 76 puerulus settlement sites, each with at least 3 collectors, at which sampling took place over at least $1 \mathrm{yr}$. There is considerable variation in the quality of the settlement data - in terms of the temporal extent, number of collectors, and the number and frequency of checks. Here, we use data that best reflects what we believe to be the normal geographic pattern of settlement. Therefore, sites that were clearly inappropriate (because of such factors as regular bouts of low salinity, remoteness from the open ocean, or inexplicably high levels of settlement) were edited out of the data used here. Also, we used data only from the main settlement months (January to September for
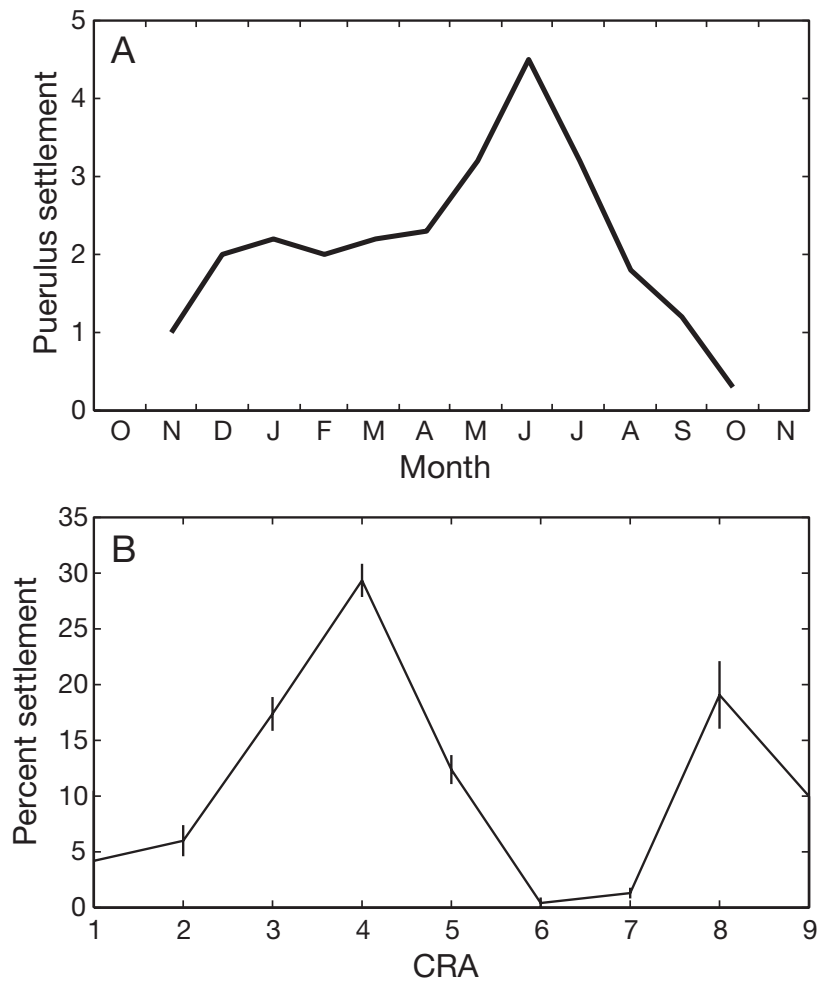

Fig. 4. Jasus edwardsii. (A) New Zealand-wide average puerulus settlement as function of time. Peak settlement occurs over the winter (June to July). (B) Percentage of annual puerulus settlement plotted by management area (CRA) ('corrected' version; see Table 1). Vertical bars indicate $\mathrm{SD}$ in observations

CRAs 4 and 5 and April to September for all others), and we omitted data from the extreme (highest and lowest) settlement years (1981, 1983, 1987, 1991, 1992, and 1999). The mean settlement per unit length of coastline was then computed for each CRA area, giving the 'base' indices of percent settlement (Table 1). However, there were additional sites sampled for less than $1 \mathrm{yr}$, results from which suggested that settlement was underestimated in CRA 1 and CRA 9 and overestimated in CRA 2. Thus, the base index was corrected to produce a 'corrected' settlement index. While the correction was somewhat subjective, it required only a small change - no more than 0.5 units of mean settlement per unit length of coastline, and then for only 3 of the CRA areas. The final index used here is the 'corrected' per cent settlement by quota management area (see Table 1 \& Fig. 4B).

Model description. We use a Lagrangian approach, where we numerically seed the model ocean with individual larvae, and use time-varying currents derived from a satellite altimeter to simulate larval paths. TOPEX/Poseidon (T/P) data from the spring of 1993 through to the end of 2003 are used here. Since settlement occurs in the second year after hatching, we can 
Table 1. Jasus edwardsii. For each quota management area, the number of collector sites, approximate length of open coastline (excluding deep embayments and estuaries and all but the larger islands), indices of mean settlement (base case and modified) per unit length of coastline, and per cent contribution to settlement (mean settlement $\times$ coastline length). Each collector site contained at least 3 collectors

\begin{tabular}{|c|c|c|c|c|c|c|}
\hline $\begin{array}{l}\text { Quota } \\
\text { management } \\
\text { area }\end{array}$ & No. sites & $\begin{array}{c}\text { Length of } \\
\text { coastline }(\mathrm{km})\end{array}$ & $\begin{array}{c}\text { Mean } \\
\text { settlement } \\
\text { (base case) }\end{array}$ & $\begin{array}{c}\text { Mean } \\
\text { settlement } \\
\text { (corrected) }\end{array}$ & $\begin{array}{c}\% \text { of total } \\
\text { settlement } \\
\text { (base case) }\end{array}$ & $\begin{array}{l}\% \text { of total } \\
\text { settlement } \\
\text { (corrected) }\end{array}$ \\
\hline CRA 1 & 3 & 519 & 0.02 & 0.50 & 1.8 & 4.2 \\
\hline CRA 2 & 14 & 739 & 0.86 & 0.50 & 11.3 & 6.0 \\
\hline CRA 3 & 7 & 294 & 3.67 & 3.67 & 19.2 & 17.4 \\
\hline CRA 4 & 13 & 580 & 3.15 & 3.15 & 32.5 & 29.4 \\
\hline CRA 5 & 7 & 1016 & 0.76 & 0.76 & 13.8 & 12.4 \\
\hline CRA 6 & 4 & 277 & 0.08 & 0.08 & 0 & 0.4 \\
\hline CRA 7 & 6 & 287 & 0.27 & 0.27 & 0.4 & 1.3 \\
\hline CRA 8 & 20 & 1112 & 1.07 & 1.07 & 21.2 & 19.1 \\
\hline CRA 9 & 2 & 1239 & 0.00 & 0.50 & 0 & 10.0 \\
\hline
\end{tabular}

simulate settlement occurring from 1995 to 2003, i.e. we simulate 9 settlement years. In each of these 9 simulations, the model is seeded in the spring of the hatching year with larvae from 382 hatching locations (Fig. 3). Each hatching location produces larvae daily for $6 \mathrm{wk}$ (see 'Model hatching and phyllosoma dispersion' for a more detailed description of location and timing), and the trajectories of these larvae are then computed through to the end of the settlement year. Because the ocean is time-varying, no 2 trajectories from any hatching location will be identical. We make the assumption that the day-to-day and year-to-year variability in the T/P data adequately reflects oceanic variability so that the modelled distribution of trajectories from each hatching location represents the likely dispersion of larva hatched there. Thus, no explicit diffusion (e.g. random walk) is added to the trajectories. Larval trajectories are computed from the satellitederived currents using a fourth-order Runge-Kutta Lagrangian advection scheme (Bellen \& Zennaro 2003).

Larval behaviour has to be added to the model to determine when (and hence where) each phyllosoma metamorphoses. We do not consider the puerulus phase explicitly, but instead the model computes 'successful' metamorphosis - defined here as metamorphosis that results in a puerulus settling. Successful metamorphosis has to take place close enough to the coast to allow the puerulus to swim to the shore given its limited reserves, and has to take place during the times of observed settlement. Successful metamorphosis is considered an index of puerulus settlement. In reality, settlement may not be absolutely proportional to metamorphosis for a variety of reasons, including varying rates of puerulus mortality and variable settlement habitat. However, including these processes in our model adds a further degree of complexity that is not warranted given the lack of data on puerulus set- tlement processes. We use a simple 2-parameter algorithm (see details in 'Model metamorphosis and settlement') to model successful metamorphosis, and assume that each puerulus settles in the same CRA area in which it metamorphosed.

There is no explicit mortality in our model because we have little information on predation or starvation rates in the ocean. If mortality rates were uniform everywhere, then mortality would not affect our results, since it would simply reduce the abundances proportionally everywhere. However, observational evidence is that mid- to late-stage phyllosomas (Stages 5 to 11) are rarely found inshore of the shelf break 4 mo or more after hatching (Booth 1994, authors' unpubl. data). Possibly the lack of inshore larvae is due to relatively high predation there compared to farther offshore. Here, we treat this by simply removing all phyllosomas that are within $20 \mathrm{~km}$ of the coast 4 to $12 \mathrm{mo}$ after hatching.

Model currents. Satellite data used here were gridded sea level anomaly maps derived from T/P and European Remote Sensing (ERS) satellite data and provided by AVISO (Archivage, Validation et Interprétation des données des Satellites Océanographiques). The gridded sea level anomalies are used to derive geostrophic surface currents. Validation of the satellite-derived currents is impractical here, and we rely on extensive treatment elsewhere for validation (e.g. Blayo et al. 1997).

Satellite orbital characteristics cannot be measured accurately, so satellite-altimeter-derived currents have to be regarded as anomalies from some independently determined mean current field (e.g. Mitchum 1994). Mean fields can be obtained from hydrographic climatologies or from numerical simulations. Because there are potentially large differences between various mean fields we tested the sensitivity of our model to the mean fields by using 3 different means. The first is 
derived from the CSIRO Atlas of Regional Seas climatology (CARS, Ridgway et al. 2002). CARS is an objectively analysed map of all conductivity-temperaturedepth (CTD) and expendable bathythermograph (XBT) profiles from the Australia-New Zealand region. The other mean fields are derived from the output of a 3-dimensional regional model of the New Zealand region (Rickard et al. 2005). This regional model was run with 2 values of horizontal diffusivity: $25 \mathrm{~m}^{2} \mathrm{~s}^{-1}$ and $6.25 \mathrm{~m}^{2} \mathrm{~s}^{-1}$, denoted here as D25 and D6.25, respectively. Horizontal diffusivity is included in these models to smooth out sub-grid scale numerical instabilities, and in general models should be run with the lowest diffusivity possible, although if the diffusivity is too low, the models become unstable. Chiswell \& Rickard (2006) compared these mean fields against drifter and hydrographic data, and concluded that while there are differences between them, both mean fields compared favourably against independent data. D6.25 may be running at the limits of numerical stability.

All 3 of the mean fields used here capture the major currents around New Zealand (Fig. 5). For a detailed comparison of the differences between these mean fields, we refer the reader to Chiswell \& Rickard (2006), who indicate that CARS underestimates the strength of the Southland Current, whereas the model fields may overestimate the strength of the East Cape Eddy.

Model hatching and phyllosoma dispersion. In each year's simulation, our model is 'seeded' in the spring of the hatching year with new larvae. The density of these new larvae is set to match estimates of larval production. There were 382 hatching locations, distributed according to the larval production per unit length of coastline (Fig. 3) and placed approximately $20 \mathrm{~km}$ from shore. In reality, hatching takes place considerably closer to shore than this, and phyllosomas are assumed to be transported out of the coastal environment by winds and other coastal processes that are not in our model. We assume that this offshore larval transport is immediate, but it could take several days.

Hatching in our model reflects observed hatching times. Phyllosomas were assumed to hatch over a $6 \mathrm{wk}$ period starting on 1 September at North Cape, and progressively delayed going south, so that off Stewart Island, hatching started 15 October. New larvae were added to the model daily during the 6 wk hatching period, so that each source shown in Fig. 3 contributes 45 larvae to the simulation. Thus, each of the 9 settlement-year simulations tracks 17190 phyllosomas.

Model metamorphosis and settlement. One of the more critical components of this work is the algorithm that determines when and where metamorphosis, and hence settlement, occurs. We do not explicitly model the puerulus phase, and instead assume that each phyllosoma that metamorphoses in the model results in a puerulus settling at the coast. In reality, there may be some metamorphosis that occurs too far offshore for the puerulus to successfully settle, but we do not allow such unsuccessful metamorphosis to occur in the model, and instead model only successful metamor-
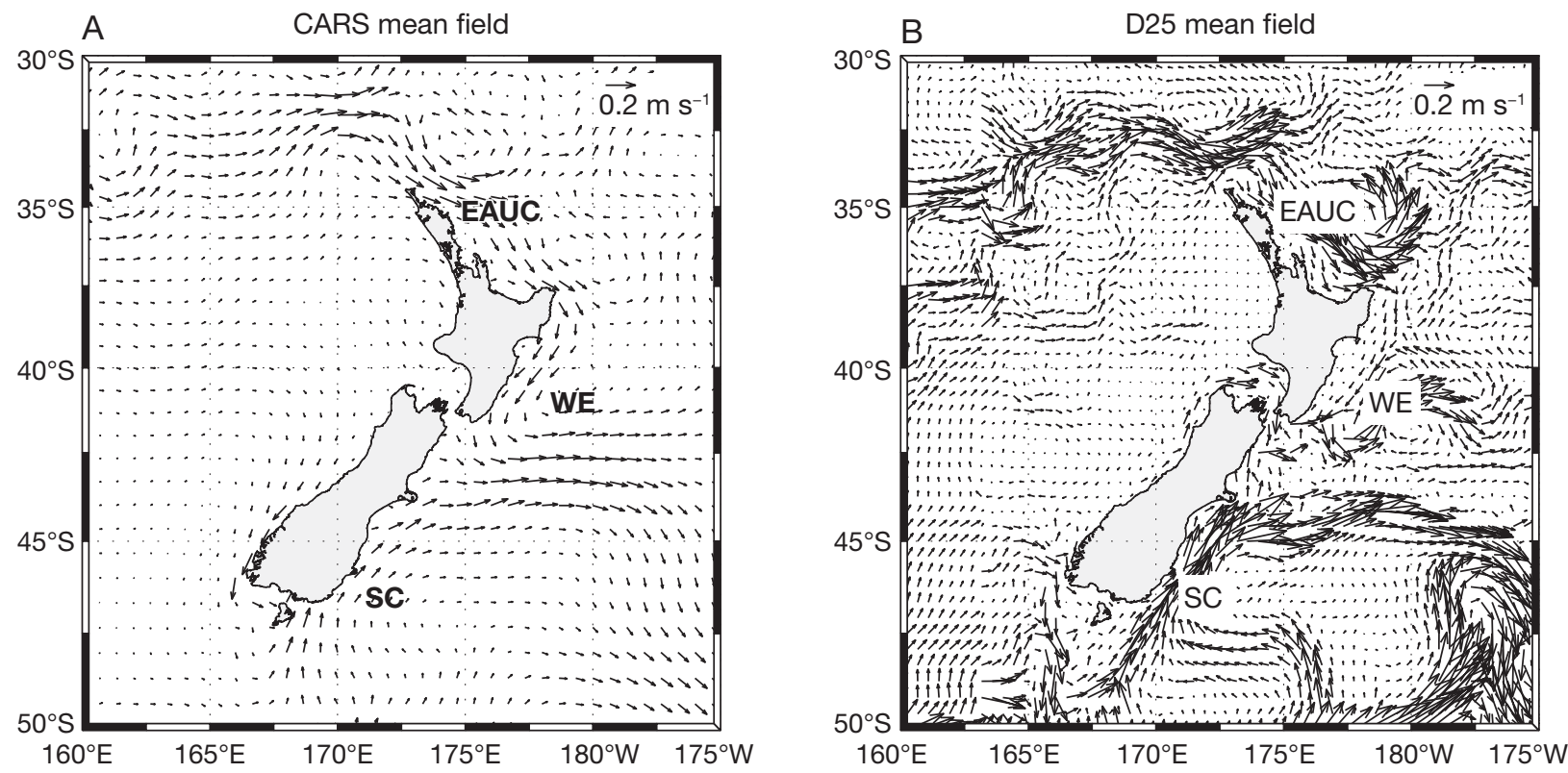

Fig. 5. Mean currents shown as vectors from the 2 of the 3 mean fields considered (see 'Methods'). (A) CSIRO Atlas of Regional Seas (CARS) climatology; (B) 3-dimensional numerical model climatology with horizontal diffusion set to $25 \mathrm{~m}^{2} \mathrm{~s}^{-1}$ (D25). Vector scale is shown in the top right of each panel. EAUC: East Auckland Current; WE: Wairarapa Eddy; SC: Southland Current 
phosis. Thus, the algorithm must get both the location and timing of metamorphosis correct.

In the ocean, there is probably some combination of external and internal factors that initiates metamorphosis. Internal factors such as interval since last moult, nutrition, and hormone levels probably determine when metamorphosis occurs, but external factors such as water temperature and food quality or quantity are also thought to be important (e.g. Jeffs et al. 2001). However, none of these factors are well understood, and we are forced to use a simple parameterised algorithm for metamorphosis.

Under our algorithm, to be allowed to metamorphose, phyllosomas had to satisfy 3 criteria: (1) the time of metamorphosis had to be within a specified settlement window, (2) the phyllosoma had to be within a specified distance from the coast, and (3) the phyllosoma had to have attained a specified energy level. Phyllosomas were allowed to metamorphose at the first opportunity when all 3 criteria were met. The settlement window was set to be 1 November in the year before the settlement year to 31 October in the settlement year. The pre-specified distance offshore, which we term the maximum metamorphosis distance and abbreviate as $m$-distance, was variable and could be any one of $50,100,150$, or $200 \mathrm{~km}$.

The requirement that phyllosomas have to achieve a

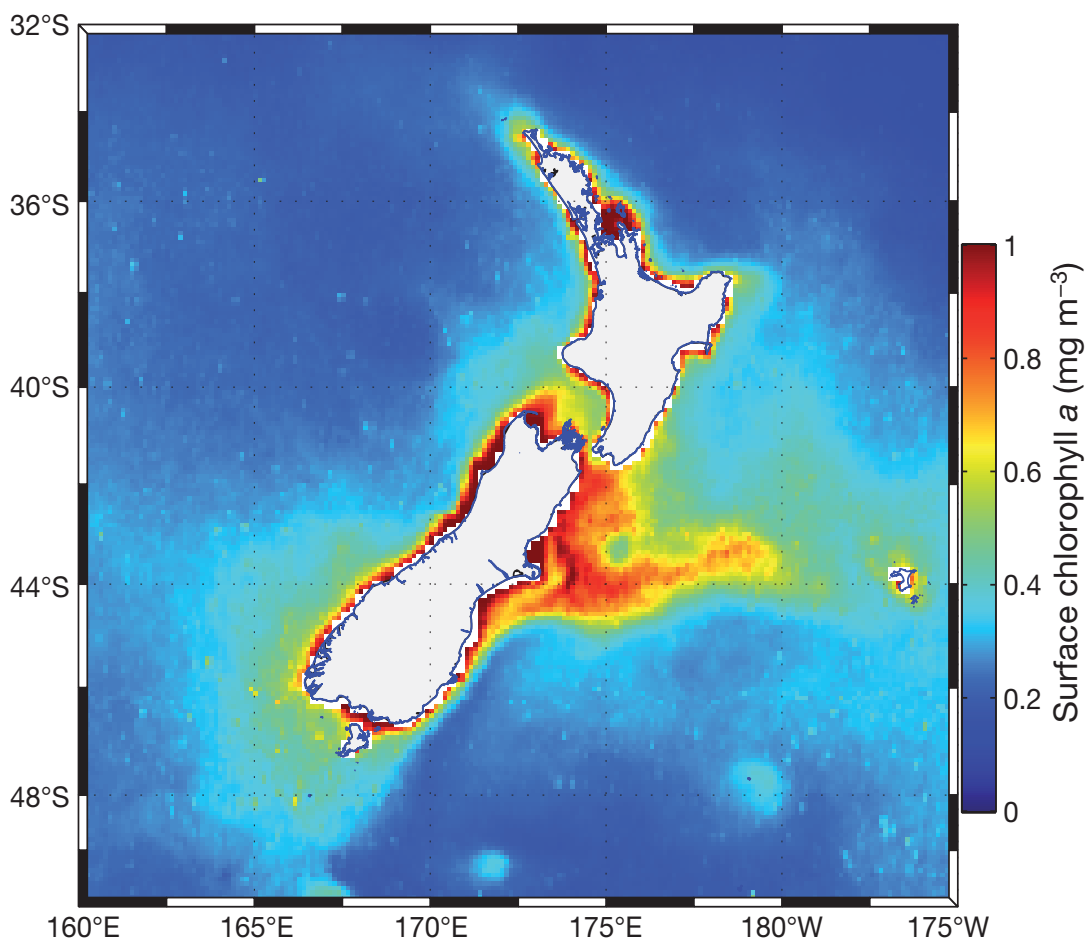

Fig. 6. Mean 1988-2003 surface chlorophyll a $\left(\mathrm{mg} \mathrm{m}^{-3}\right)$ derived from the Sea-viewing Wide Field-of-view Sensor (SeaWiFS) satellite. Productive areas are primarily near the coast and in the Subtropical Front specified energy level before metamorphosis reflects the presumption that pueruli rely on stored energy in the form of lipids for their migration to the coast (Jeffs et al. 2001), and there is likely to be a minimum level of energy needed before metamorphosis can occur. Phyllosomas are carnivorous (Booth \& Phillips 1994), probably feeding on items such as copepods and salps, but there is no measure of this secondary production. Instead, we use mean surface chlorophyll a values derived from the SeaWiFS (Sea-viewing Wide Fieldof-view Sensor) satellite as a measure of phyllosoma prey (Fig. 6). The relationship between surface chlorophyll $a$ and phyllosoma energy uptake is likely to be highly complex, and include, for example, a time lag between primary and secondary production. However, this complexity is well beyond our ability to model, so we assume that energy uptake in phyllosomas is proportional to surface chlorophyll a levels. Thus, the accumulated energy, $e$, for a phyllosoma at time $t$ after hatching is given by:

$$
e(t)=\int_{0}^{t} C h l(\tau) \mathrm{d} \tau
$$

where $C h l$ is surface chlorophyll a experienced by the phyllosoma as it drifts. Metamorphosis under our algorithm is only allowed when $e$ is greater than some critical energy level, $c$. Strictly speaking, accumulated energy has units of chlorophyll a density times time (i.e. $\mathrm{mg} \mathrm{m}^{-3} \mathrm{~d}$ ). However, since we are using this quantity as a proxy for internal energy, we consider e to be dimensionless.

While simplistic, this algorithm achieves 2 things: first, many phyllosomas do not achieve the critical level, and never metamorphose. Second, the algorithm spreads out the times of metamorphosis. As a result, metamorphosis locations are sensitive to our choice of $C$, so that $c$ can be used to 'tune' the model (see 'Fitting modelled to observed settlement').

An example of a model run for one simulated phyllosoma is provided in Fig. 7. The phyllosoma hatched in CRA 2 in September 1994. Inset panels show the surface chlorophyll a experienced by this phyllosoma and its consequent energy accumulation. Horizontal lines show several critical energy levels $\boldsymbol{C}$. Initial chlorophyll a levels were about $0.55 \mathrm{mg} \mathrm{m}^{-3}$ while the phyllosoma was in coastal waters, and then gradually decreased as the phyllosoma drifted offshore. Accumulated energy correspondingly rose steeply initially and then flattened off. In this example, the phyllo- 


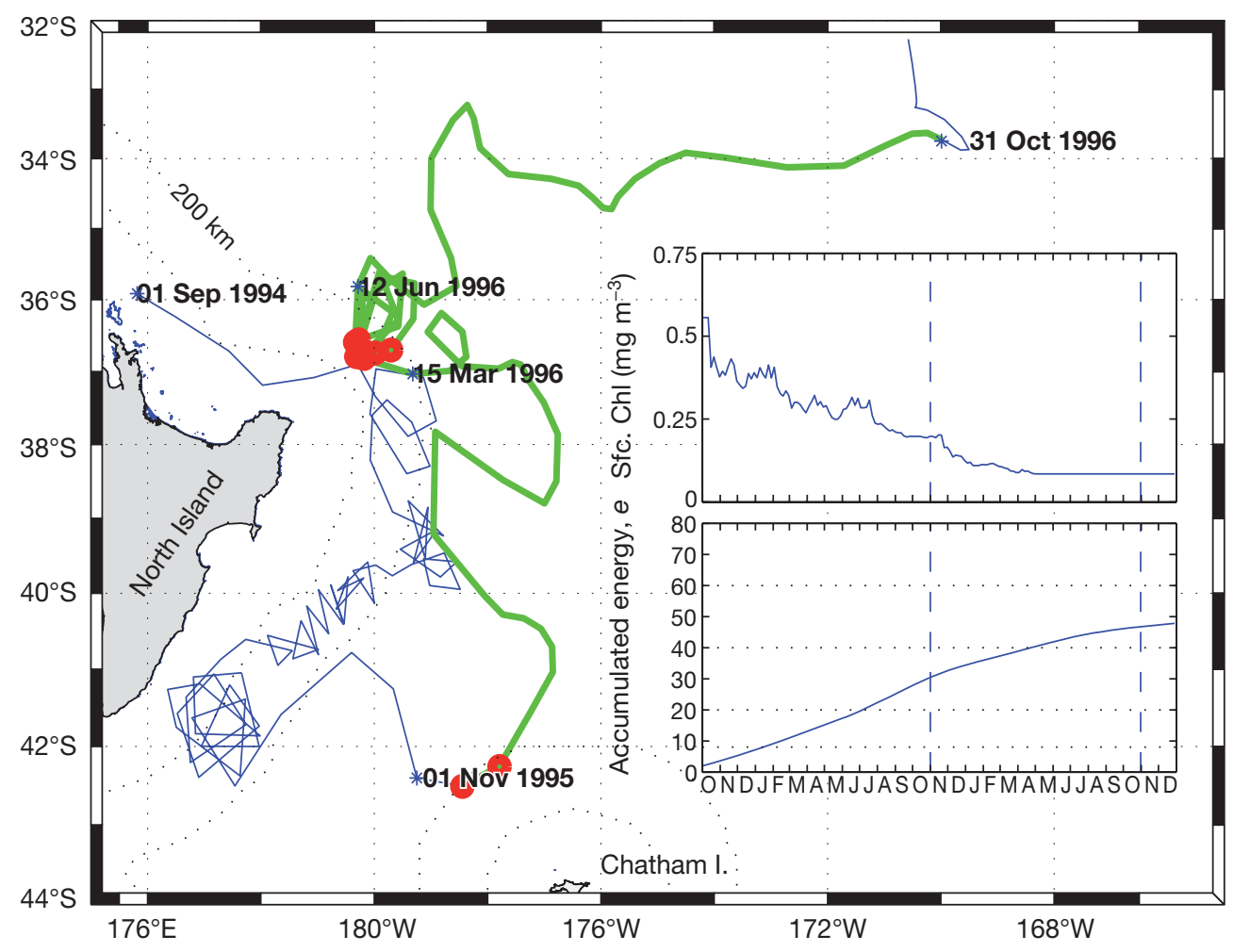

Fig. 7. Jasus edwardsii. Simulated trajectory for a phyllosoma hatched 1 September 1994 ; the trajectory appears jagged because the phyllosoma's location is saved every $5 \mathrm{~d}$. The portion of the trajectory shown in green indicates the phyllosoma path during the window for settlement (1 November 1995 to 31 October 1996). The phyllosoma's positions at various dates are labelled. Dotted lines indicate 100 and $200 \mathrm{~km}$ offshore as labelled. Inset upper panel: Surface chlorophyll a (Sfc. Chl) concentration experienced by the simulated phyllosoma during its lifetime. Inset lower panel: Accumulated energy for the phyllosoma. Vertical dashed lines show the settlement window. Horizontal lines show several critical energy levels, $c$

soma was within $200 \mathrm{~km}$ of the Chatham Islands just after the beginning of the settlement window (1 November 1995), but it then moved north and stayed more than $200 \mathrm{~km}$ offshore until 15 March 1996, when it began a series of loops that periodically brought it to within $200 \mathrm{~km}$ of the coast. Under our algorithm metamorphosis occurs at the first instance during the settlement window when the phyllosoma has enough energy and is within $m$-distance of the coast. For this example, for an $\mathrm{m}$-distance of $200 \mathrm{~km}$ and $c=0$, metamorphosis would occur in CRA 6 (Chatham Islands) on 1 November 1995. For $c=40$ metamorphosis would occur in CRA 2 during one of the loops in April 1996. For $C=60$ (or for an $\mathrm{m}$-distance of $100 \mathrm{~km}$ ) the phyllosoma would never metamorphose.

Fitting modelled to observed settlement. Because we have 3 mean current fields and our metamorphosis algorithm has 2 free parameters, we need to determine which choice of parameters gives the most accurate results. We do this by comparing modelled metamorphosis (hence settlement) averaged over the 9 simulated settlement years with observed settlement of pueruli derived from collector observations. In essence, we tune the model so that the modelled settlement in each quota management area (as a percentage of the total) best matches the corrected settlement distribution (Table 1).

Simulations were run for each settlement year from 1995 to 2003, using each of the 3 mean fields. Each trajectory was then examined to see if that phyllosoma metamorphosed under the metamorphosis algorithm, using $m$-distances of 50,100 and $150 \mathrm{~km}$ and critical energy levels, $C$, of 0 to 100 in steps of 10 . Thus, for each year we had 99 possible final solutions in a 3dimensional parameter space (mean field, $m$-distance, and $C$ ).

Each of the 99 possible final solutions has a distribution of metamorphosis in time and space, but not all are equally valid. We assume that the best solution is the one where modelled settlement best matches observed settlement in both space (i.e. by CRA) and in time (i.e. time of year). This best solution is determined by computing goodness-of-fit parameters, and choosing the solution with the best fit. However, before making the fit, it is illustrative to demonstrate the impact each parameter choice has on metamorphosis locations. 
The spatial distribution of metamorphosis is generally similar for all mean current fields, with highest levels of modelled metamorphosis occurring around the east coast of the North Island (Fig. 8). With $c=0$, $m=100 \mathrm{~km}$, and the CARS mean current field, a total of 15164 phyllosomas metamorphosed (i.e. about 10\% of all larvae). Total numbers of metamorphosed phyllosomas for the other mean current fields are similar. However, there are some differences in the results among the mean current fields. For example, metamorphosis levels are higher using D25 between Cook Strait and Kaikoura, and near Fiordland than using CARS.

Varying the parameter $C$ changes the spatial distribution of settlement (Fig. 9). Using the CARS mean field tends to overestimate settlement in CRA 8 and 9 (i.e. the south of the South Island, and west coast of both islands), compared to the observed distribution. However, using the D25 model mean tends to result in underestimated settlement in CRA 1 and 2 (northern North Island) and overestimated settlement in CRA 3 and 4 (southeast North Island). All models tend to overestimate settlement in CRA 6 (Chatham Islands). The best agreement between simulated and observed distributions occurs for $C=30$ using CARS and for $c=60$ using D25 (thick dashed lines).

Changing $C$ also affects the timing of settlement (Fig. 10). For $C=0$ (i.e. there is effectively no energy requirement for metamorphosis), the timing of settlement peaks at the beginning of the settlement window.
This reflects the fact that all phyllosomas can metamorphose as soon as they return to within $100 \mathrm{~km}$ of the coast after the start of the settlement window. As $C$ increases, the timing of metamorphosis shifts to later in the year because phyllosomas need time to accumulate energy; the total level of metamorphosis also decreases because some phyllosomas never attain the critical level. At extreme values of $c$ (e.g. 90) very few phyllosomas metamorphose.

To determine the best fit solutions, we defined 2 goodness-of-fit-parameters. The spatial goodness-offit, $f_{S}$, was defined as the weighted mean differencesquare between the modelled and observed settlement index:

$$
f S=\sum_{i=1} w_{i}\left|o_{i}-e_{i}\right|^{2}
$$

where $o_{i}$ is the corrected observed value shown in Fig. $4 \mathrm{~B}, e_{i}$ is the estimated value, and $w_{i}$ is a set of weights inversely proportional to the estimated error in $o$.

Similarly, the temporal goodness-of-fit parameter, $\mathrm{ft}$, was defined as the mean difference-square between modelled and observed monthly values of settlement:

$$
f t=\sum_{i=1}^{i=12}\left|o_{i}-e_{i}\right|^{2}
$$

where $o_{i}$ was the monthly observed settlement shown in Fig. 4A and $e_{i}$ is the estimated monthly value. Because the total number of phyllosomas metamorphosing decreases as $C$ increases, the observed and
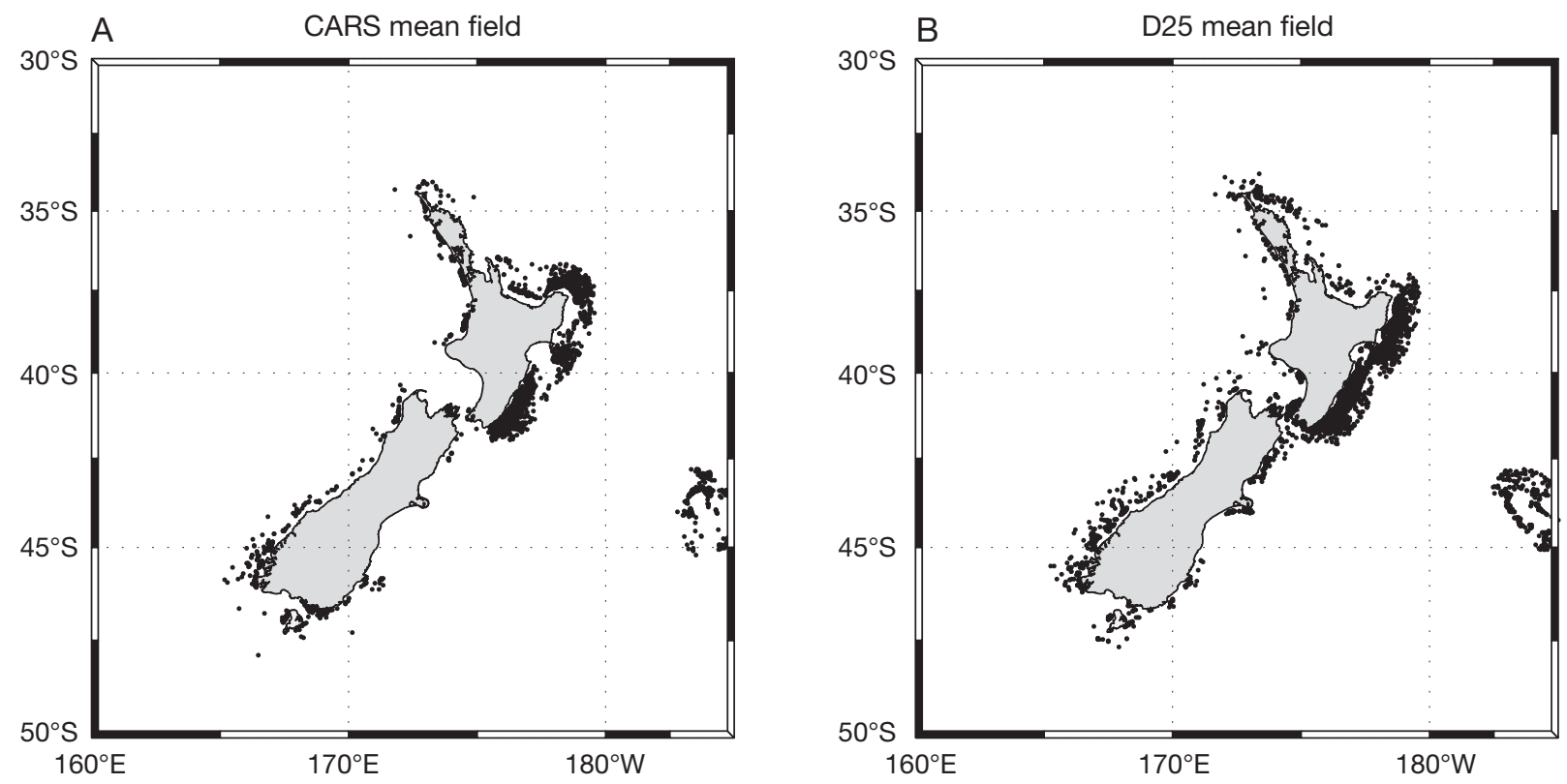

Fig. 8. Jasus edwardsii. Metamorphosis locations for the (A) CARS and (B) D25 mean fields with critical energy levels $(C)=0$ and maximum metamorphis distance $(m)=100 \mathrm{~km}$. Each metamorphosis is shown as a dot, and the density of dots roughly indicates the density of metamorphosis (in some areas the dots overlap). See Fig. 5 for definitions of CARS and D25 

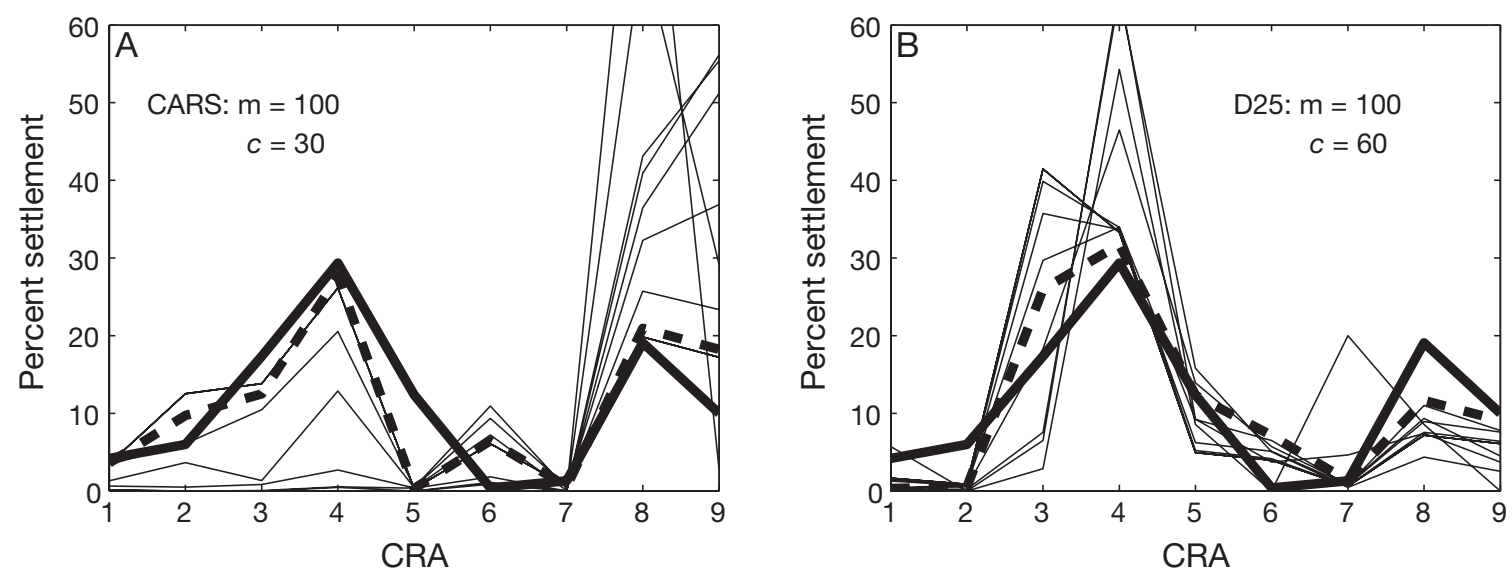

Fig. 9. Jasus edwardsii. Impact of varying critical energy levels, $C$, on distribution of settlement around the coast. Successful metamorphosis as a percentage of total plotted as a function of quota management area (CRA) for the (A) CARS and the (B) D25 mean fields using a metamorphosis distance, $m$, of $100 \mathrm{~km}$. (See Fig. 5 for definition of CARS and D25.) Thick solid line shows the observed value of the settlement index (shown in Fig. 4). Thin lines indicate simulated values for various values of $c$. Thick dashed lines indicate best fits between simulated successful metamorphosis and observed settlement within each panel. These best fits occur for $c=30$ (CARS) and $c=60$ (D25)
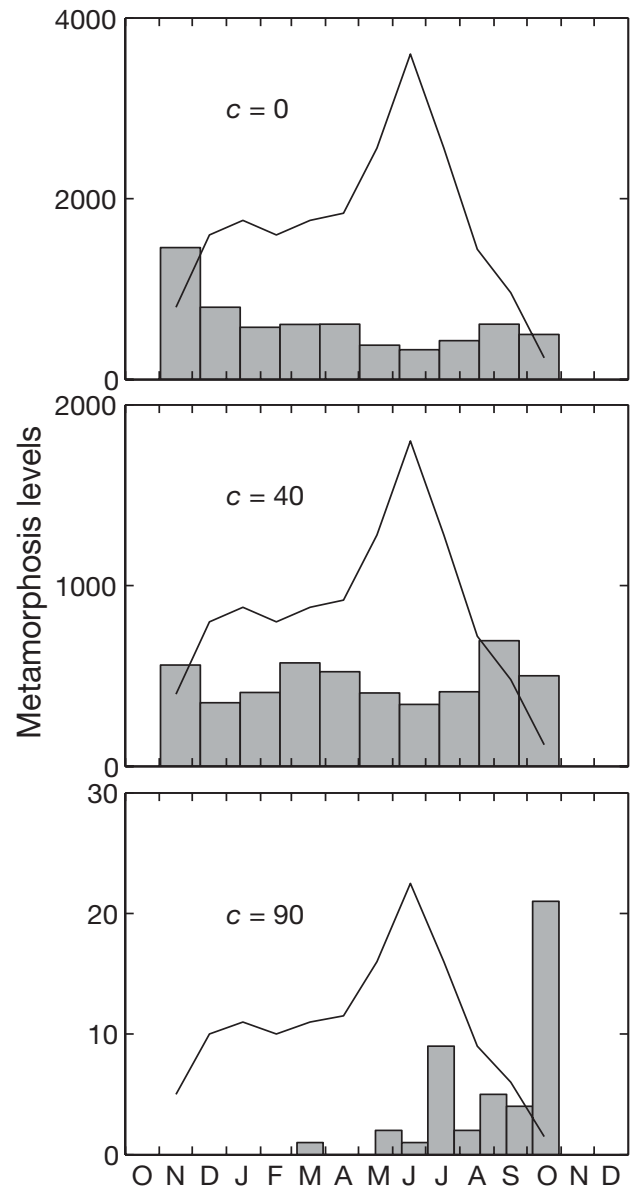

Fig. 10. Jasus edwardsii. Histograms of time of metamorphosis for several critical energy levels, $c$, using the D25 mean field and $m$-distance of $100 \mathrm{~km}$ (see 'Methods'). Thin line is observed settlement as a function of time as shown in Fig. 4, but rescaled to suit estimated monthly values were normalised to have the same sum.

When plotted against the $c$-value, the goodness-offit shows 2 groups (Fig. 11). The CARS solutions represent one group and both model mean fields represent the second group. There is relatively little difference between the solutions for the 2 model mean fields (D6.25 and D25). Similarly, while both $f s$ and $f t$ are sensitive to $c$, they show relatively little sensitivity to the choice of $m$-distance except at high values of $c$ for the model mean fields (each line in Fig. 11 is a constant value of $m$ ).

The best spatial fits are obtained using the model mean fields with $c=60$, regardless of $m$-distance. The best temporal fits are obtained with the CARS mean field, with $c<60$. The overall sensitivity of $f t$ to the parameter range is small compared to that of $f_{s}$ ( $f t$ ranges from 1.1 to 1.25 whereas $f s$ ranges from 6.4 to 32 ), which suggests that one should give more weight to fs than $f t$ in deciding the best set of parameters.

Analyses of the mean fields made elsewhere (Chiswell \& Rickard 2006) suggest that the circulation in the CARS mean field around the South Island, including the Southland Current, is too slow compared with independent observations. Thus, we suspect that in simulations made with the CARS mean field, phyllosomas tend to remain around the South Island longer than they do in reality, with more entrainment of phyllosomas than there should be-leading to higher settlement (Fig. 9). Conversely, the numerical models tend to include an East Auckland Current that separates from the coast too early, and an East Cape Eddy that is too strong. In these simulations, phyllosomas in these regions probably get dispersed faster than in 

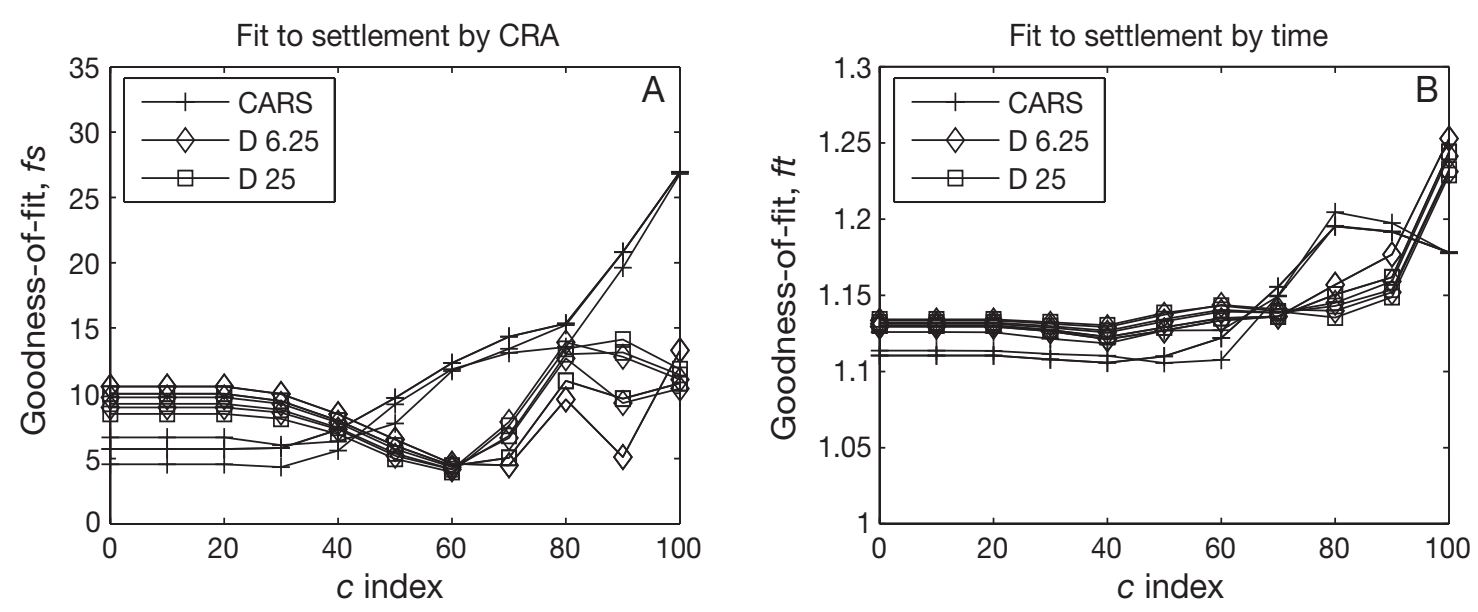

Fig. 11. Jasus edwardsii. Spatial and temporal goodness-of-fit parameters plotted as a function of the critical energy level, $C$, in the metamorphosis algorithm. (A) Goodness-of-fit computed by management area (CRA), fs. (B) Goodness-of-fit computed in time, $f t$ (see 'Methods' for definitions). Simulations made with CARS mean field and 3 values of $m$-distance ( $\longrightarrow$-). Simulations made with D6.25 ( $\diamond)$ and D25 ( $\square-)$ mean fields

reality, and this leads to reduced settlement in CRAs 1 and 2, as seen in Fig. 9.

For this reason, we consider it best to use the numerical model mean fields for CRAs 3 to 9, and the CARS mean flow for CRAs 1 and 2. In order to estimate the sensitivity of our results to our choice in parameters, we compute the average and standard deviation in the results from a range of solutions. Since the $f s$ and $f t$ parameters are more sensitive to the choice of $c$ than $m$-distance, we average the results over all $m$ distances, but only over a range in $c$ suggested by Fig. 11. For CRAs 1 and 2, we average the CARS mean flow simulations with all 3 values of $m$-distance and with $c$ ranging from 0 to 20 . For the remaining quota management areas, we average over both D6.25 and D25 model mean fields, all $m$-distances, and $c$ ranging from 40 to 60 .

\section{RESULTS}

The fate of phyllosomas released in different areas is variable (Table 2). For example, of the successful phyllosomas hatched off the east coast of the North Island (CRAs 3 and 4), virtually all settlement is local (i.e. in the same or adjacent CRA), whereas of the successful phyllosomas hatched near Fiordland (CRA 8) only about $50 \%$ settle locally and the remainder widely disperse.

Correspondingly, there is a similar variability in the origin of settlement in each CRA. Settlement in some CRAs is predominantly from local hatching (e.g. CRA 8), while settlement in other areas is from much wider hatching (e.g. CRA 3). These results support the hypothesis of complex source-sink relationships among areas.

Table 2. Jasus edwardsii. Sinks: fate of phyllosomas hatched in each quota management area. Table should be read as rows only. For example, $18 \%$ of phyllosomas hatched in CRA 1 that successfully metamorphose do so in CRA 2 . Errors are 1 SD

\begin{tabular}{|c|c|c|c|c|c|c|c|c|c|}
\hline \multirow{2}{*}{$\begin{array}{l}\text { Source quota } \\
\text { management } \\
\text { area }\end{array}$} & \multirow[b]{2}{*}{ CRA 1} & \multirow[b]{2}{*}{ CRA 2} & \multirow[b]{2}{*}{ CRA 3} & \multicolumn{3}{|c|}{ estination quota management area } & \multirow[b]{2}{*}{ CRA 7} & \multirow[b]{2}{*}{ CRA 8} & \multirow[b]{2}{*}{ CRA 9} \\
\hline & & & & CRA 4 & CRA 5 & CRA 6 & & & \\
\hline CRA 1 & $1 \pm 1$ & $18 \pm 5$ & $12 \pm 7$ & $46 \pm 11$ & $1 \pm 0$ & $16 \pm 12$ & 0 & 0 & $8 \pm 5$ \\
\hline CRA 2 & 0 & $23 \pm 11$ & $39 \pm 21$ & $33 \pm 14$ & 0 & $4 \pm 3$ & 0 & 0 & 0 \\
\hline CRA 3 & 0 & 0 & $59 \pm 4$ & $38 \pm 3$ & $1 \pm 1$ & $2 \pm 1$ & 0 & 0 & 0 \\
\hline CRA 4 & 0 & 0 & $58 \pm 4$ & $37 \pm 2$ & $0 \pm 1$ & $4 \pm 2$ & 0 & 0 & 0 \\
\hline CRA 5 & 0 & 0 & $53 \pm 6$ & $29 \pm 1$ & $2 \pm 1$ & $17 \pm 6$ & 0 & 0 & 0 \\
\hline CRA 6 & 0 & 0 & $28 \pm 9$ & $9 \pm 1$ & 0 & $63 \pm 10$ & 0 & 0 & 0 \\
\hline CRA 7 & 0 & 0 & $39 \pm 9$ & $20 \pm 4$ & $1 \pm 1$ & $39 \pm 13$ & 0 & 0 & 0 \\
\hline CRA 8 & $2 \pm 1$ & 0 & 0 & $25 \pm 1$ & $21 \pm 4$ & $0 \pm 1$ & $2 \pm 1$ & $30 \pm 1$ & $19 \pm 3$ \\
\hline CRA 9 & $5 \pm 2$ & $5 \pm 1$ & $20 \pm 1$ & $36 \pm 4$ & $4 \pm 2$ & $6 \pm 4$ & 0 & $6 \pm 1$ & $17 \pm 4$ \\
\hline
\end{tabular}



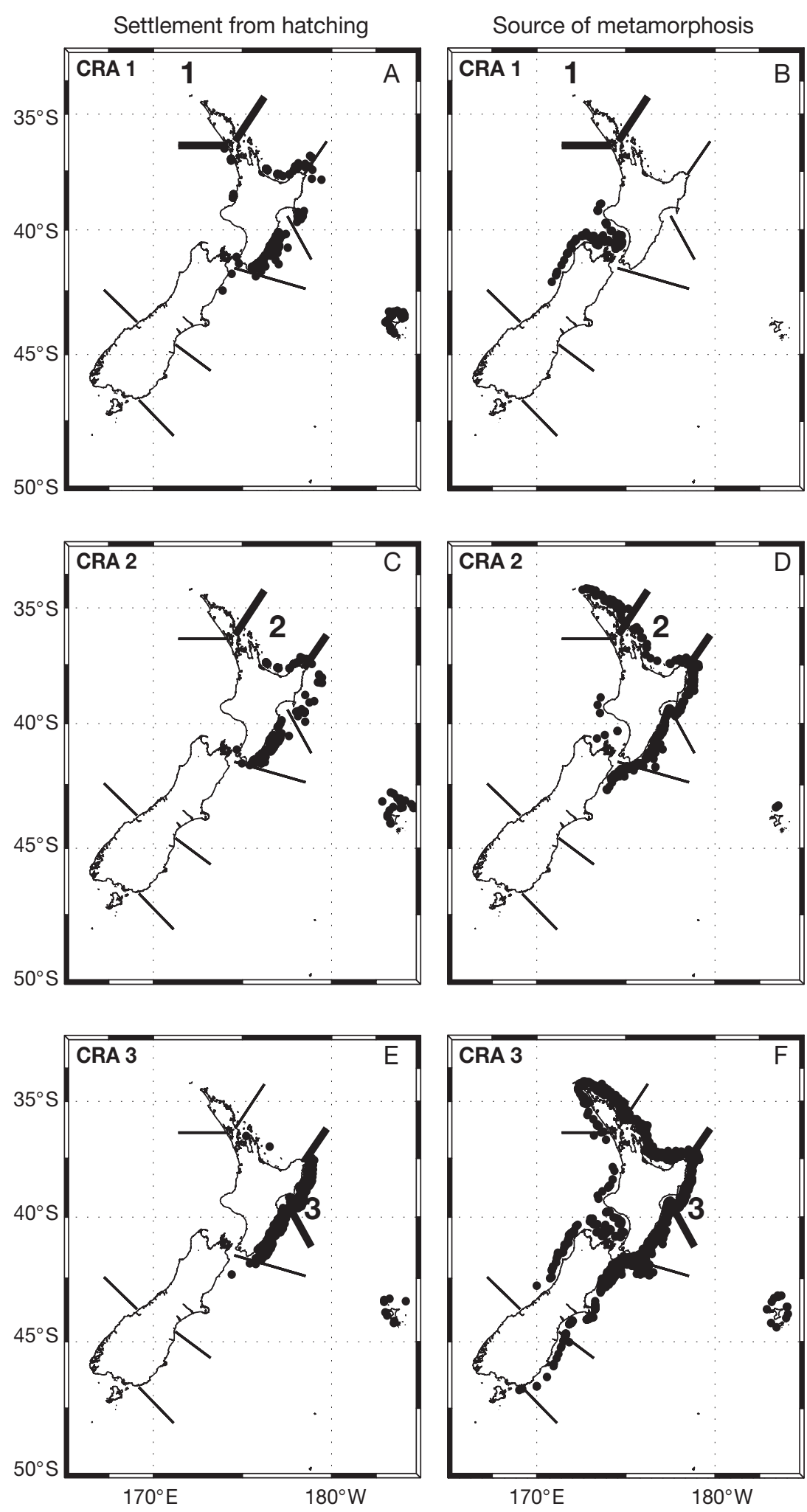

Fig. 12. Jasus edwardsii. (A,C,E) Successful settlement locations for phyllosomas hatched in denoted quota management area. $(B, D, F)$ Hatching locations for phyllosomas that successfully metamorphose in denoted quota management area. $(\mathrm{A}, \mathrm{B}) \mathrm{CRA} 1$; $(\mathrm{C}, \mathrm{D}) \mathrm{CRA} 2$; $(\mathrm{E}, \mathrm{F}) \mathrm{CRA} 3$. Thick lines show limits for denoted CRA

\section{Sources and sinks by quota management area (CRAs 1 to 9) (Figs. 12 to 14)}

CRA 1. Because of the East Auckland and East Cape Currents, most phyllosomas hatched in CRA 1 become entrained in the East Cape and Wairarapa Eddies, and eventually settle downstream in CRAs 2, 3 and 4 (Figs. 12 \& 13). Our model suggests that approximately one-sixth of phyllosomas hatched in CRA 1 settle at the Chatham Islands. If we were to assume no settlement in the Chatham Islands, then the other values for successful phyllosomas from CRA 1 would increase proportionally. Most settlement in CRA 1 originates from the south, mainly from the west coast of both islands (note that the contribution from CRA 4 indicated in the table comes from that part of the CRA area that extends westwards through Cook Strait).

CRA 2. Because CRA 2 is just downstream from CRA 1, the destination quota management areas for CRA 2 are similar to those of CRA 1. Most successful phyllosomas become entrained in the Wairarapa Eddy and settle along the southeast coast of the North Island, in CRAs 3 and 4. The origins for CRA 2, however, appear markedly different from those for CRA 1. CRA 2 is closer to the Wairarapa Eddy, so there is more likelihood that phyllosomas entrained in the Wairarapa Eddy settle in CRA 2 than in CRA 1. There also appears to be significant settlement originating from CRA 1. As a consequence, the sources for settlement in CRA 2 extend from North Cape to Kaikoura. CRA 9 does not appear to be a significant source.

CRA 3. Almost all successful phyllosomas from CRA 3 settle in CRAs 3 and 4. This is because almost all phyllosomas hatched in this quota management area become entrained in the Wairarapa Eddy. Most settlement in CRA 3 originates from the east coast of the North Island (CRAs 2 to 5), with small contributions from CRAs 1 and 9.

CRA 4. CRA 4 shows very similar patterns of destination and origin to CRA 3. Successful phyllosomas from CRA 4 settle mainly along the east coast of the North Island. Settlement in CRA 4 mostly 
originates from the east coast of central New Zealand (CRAs 2 to 5) - but one-fifth of the settlement originates from CRA 8, mainly Fiordland.

CRA 5. CRA 5 appears to be a transition zone. As for the east coast North Island quota management areas, successful phyllosomas hatched in this quota management area tend to become entrained in the Wairarapa Eddy and settle along the east coast of the North Island. However, this quota management area appears to be too far south of the Wairarapa Eddy to acquire many phyllosomas from entrainment in that eddy, and the model suggests that the majority of settlement in CRA 5 originates from Fiordland.

CRA 6. Most successful phyllosomas hatched in the Chatham Islands settle in the islands, but about $37 \%$ of successful phyllosomas settle on the east coast of the North Island, in CRAs 3 and 4. Similarly, well over half of settlement in CRA 6 originates from the main islands of New Zealand (Table 3).

CRA 7. Almost all successful phyllosomas hatched in CRA 7 settle along the east coast of the North Island and at the Chatham Islands (Fig. 14, Table 2). This is primarily because of the strong Southland Current, which advects larvae quickly away from the region. Similarly, because of the Southland Current, almost all settlement in CRA 7 originates from farther upstream, in Fiordland.

CRA 8. Approximately one-third of the successful phyllosomas hatched in CRA 8 (mostly from Fiordland) settle locally in CRA 8, and about half of successful phyllosomas settle along the east coast of central New Zealand, in CRAs 4 and 5. Virtually all the settlement in CRA 8 originates from the southwest coast of the South Island.

CRA 9. Successful phyllosomas hatched in CRA 9 area settle mostly along the northeast coast of the North Island, but about one-sixth remain in CRA 9, to settle locally. Virtually all settlement in this quota management area is sourced from CRAs 8 and 9 .

\section{DISCUSSION}

\section{Model limitations}

We have little choice in the model physics; we are principally limited to choosing the best mean field. In contrast, since there is little understanding of the physiology of phyllosoma development, there is virtually unlimited scope for developing the biological algorithms. With such uncertainty, it becomes vital to tune the model to reality, and we have chosen to validate the model by comparing the simulated settlement by quota management area with settlement observed from puerulus collectors. It is encouraging that we can obtain good agreement with the observations (Fig. 10), but it is perhaps worth making subjective estimates of the model's potential limitations.

The numerical phyllosomas are treated as passive drifters in the surface currents. That is, they do not swim horizontally and their trajectories are determined solely by the currents. This is a common assumption in the treatment of larval dispersal (e.g. Black 1994, Griffin et al. 2001), and there is little reason to believe Jasus edwardsii phyllosomas behave otherwise, at least until the late stages of their development. Chiswell \& Booth $(1999,2005)$ suggested that $J$. edwardsii phyllosoma may exhibit directed swimming towards the coast during the last few weeks of their development, but there is not enough specific information on this behaviour to warrant incorporating it in the present study. If late-stage swimming does occur, it may increase successful metamorphosis rates by bringing metamorphosis closer inshore by about $40 \mathrm{~km}$ (Chiswell \& Booth 2005). However, because of the general insensitivity of the results to $m$, this is unlikely to affect our conclusions.

There is some evidence that late-stage phyllosomas exhibit diel migration, descending as deep as $100 \mathrm{~m}$

Table 3. Jasus edwardsii. Sources of settlement in each quota management area. Table should be read as rows. For example, CRA 1 gets $14 \%$ of its settlement from CRA 4, and $80 \%$ from CRA 9. Errors are 1 SD

\begin{tabular}{|c|c|c|c|c|c|c|c|c|c|}
\hline \multirow{2}{*}{$\begin{array}{l}\text { Destination } \\
\text { quota } \\
\text { management } \\
\text { area }\end{array}$} & \multirow[b]{2}{*}{ CRA 1} & \multirow[b]{2}{*}{ CRA 2} & \multirow[b]{2}{*}{ CRA 3} & \multicolumn{3}{|c|}{ Source quota management area } & \multirow[b]{2}{*}{ CRA 7} & \multirow[b]{2}{*}{ CRA 8} & \multirow[b]{2}{*}{ CRA 9} \\
\hline & & & & CRA 4 & CRA 5 & CRA 6 & & & \\
\hline CRA 1 & $4 \pm 3$ & $1 \pm 2$ & $1 \pm 1$ & $14 \pm 2$ & $0 \pm 1$ & $0 \pm 1$ & $0 \pm 1$ & $0 \pm 1$ & $80 \pm 5$ \\
\hline CRA 2 & $19 \pm 2$ & $20 \pm 4$ & $28 \pm 0$ & $24 \pm 3$ & $7 \pm 2$ & $1 \pm 1$ & $0 \pm 1$ & $0 \pm 1$ & $1 \pm 0$ \\
\hline CRA 3 & $8 \pm 2$ & $10 \pm 2$ & $25 \pm 2$ & $25 \pm 1$ & $25 \pm 4$ & $1 \pm 0$ & $1 \pm 1$ & $0 \pm 1$ & $6 \pm 1$ \\
\hline CRA 4 & $8 \pm 2$ & $12 \pm 2$ & $17 \pm 1$ & $16 \pm 1$ & $15 \pm 2$ & $0 \pm 1$ & $1 \pm 0$ & $21 \pm 3$ & $11 \pm 2$ \\
\hline CRA 5 & $0 \pm 1$ & $1 \pm 1$ & $1 \pm 1$ & $1 \pm 1$ & $4 \pm 1$ & $0 \pm 1$ & $0 \pm 1$ & $87 \pm 2$ & $6 \pm 2$ \\
\hline CRA 6 & $0 \pm 1$ & $1 \pm 1$ & $6 \pm 1$ & $13 \pm 2$ & $51 \pm 1$ & $10 \pm 3$ & $8 \pm 1$ & $2 \pm 1$ & $10 \pm 4$ \\
\hline CRA 7 & $0 \pm 1$ & $0 \pm 1$ & $0 \pm 1$ & $0 \pm 1$ & $0 \pm 1$ & $0 \pm 1$ & $0 \pm 1$ & $95 \pm 1$ & $5 \pm 1$ \\
\hline CRA 8 & $0 \pm 1$ & $0 \pm 1$ & $0 \pm 1$ & $0 \pm 1$ & $0 \pm 1$ & $0 \pm 1$ & $0 \pm 1$ & $93 \pm 1$ & $7 \pm 1$ \\
\hline CRA 9 & $0 \pm 1$ & $0 \pm 1$ & $0 \pm 1$ & $0 \pm 1$ & $0 \pm 1$ & $0 \pm 1$ & $0 \pm 1$ & $74 \pm 6$ & $25 \pm 6$ \\
\hline
\end{tabular}


during the day (Bradford et al. 2005). Currents at $100 \mathrm{~m}$ will be slightly different from the surface currents, but we cannot model the differences accurately, nor do we know the details of larval diel migration well enough to warrant including this process in our model.
Our model assumes no mortality, either from starvation or predation. This assumption is equivalent to spatially and temporally constant mortality. Starvation may be high for phyllosomas that are transported far from the coast into oligotrophic waters. Conversely,
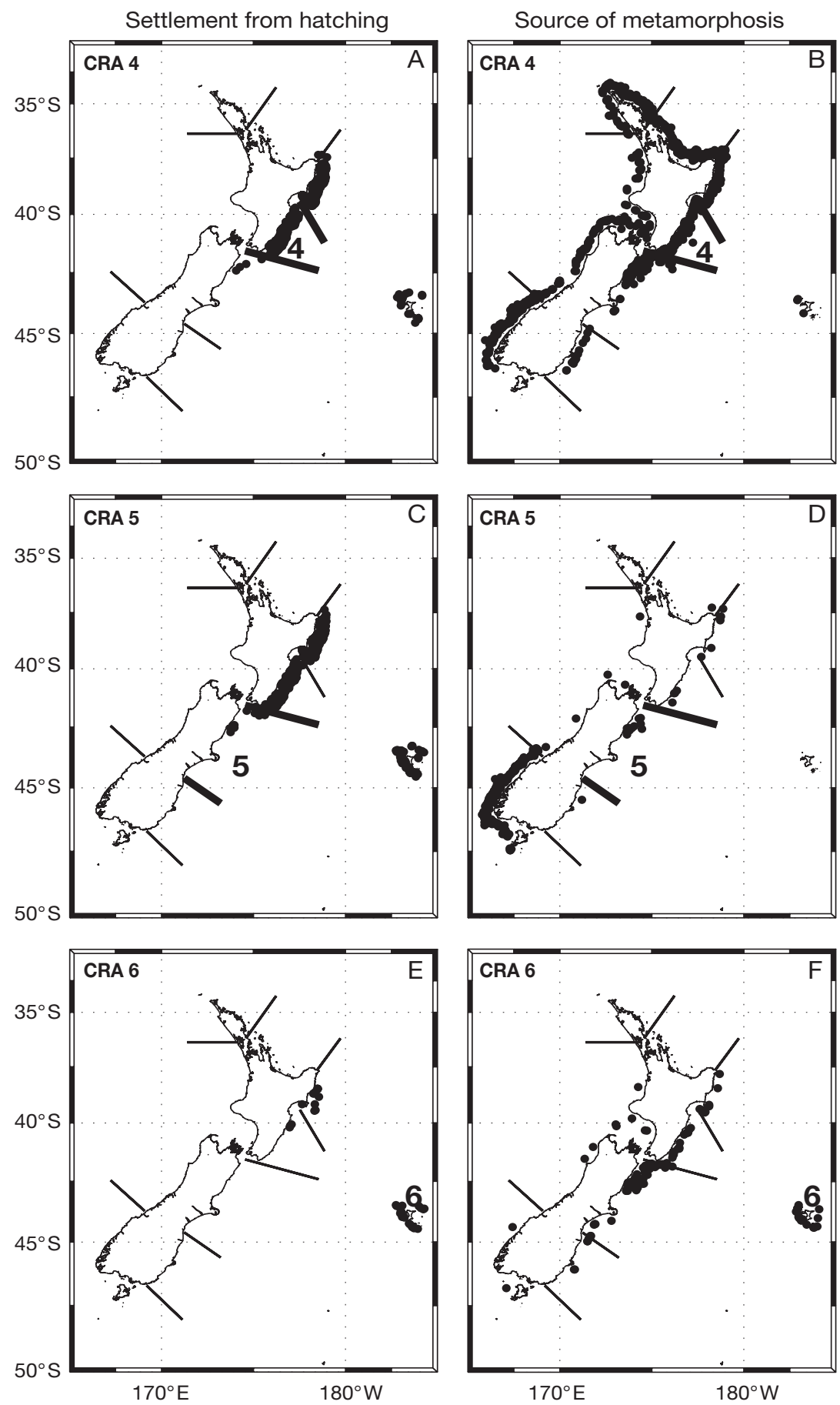

Fig. 13. Jasus edwardsii. Jasus edwardsii. (A,C,E) Successful settlement locations for phyllosomas hatched in denoted quota management area. (B,D,F) Hatching locations for phyllosomas that successfully metamorphose in denoted quota management area. (A,B) CRA 4; (C,D) CRA 5; (E,F) CRA 6. Thick lines show limits for denoted CRA predation rates may be higher in productive regions. Without any information on prey, predators, feeding and starvation, adding mortality to the model is unwarranted, and except for removing phyllosomas that remained within $20 \mathrm{~km}$ of the coast 4 to 12 mo after hatching, the model allows phyllosomas to survive indefinitely.

The final results were obtained using a mean of several solutions. This simulation captures the main features of the observed settlement: settlement is highest in CRAs 3 and 4 (East Cape to Wellington), with each of these quota management areas accounting for about $25 \%$ of total settlement. CRA 8 (particularly Fiordland) has the next highest settlement, accounting for about $10 \%$ of the total settlement.

All the models overestimate settlement on the Chatham Islands. We may be overestimating metamorphosis near the islands due to inadequacies in the metamorphosis algorithm, or we may be estimating metamorphosis reasonably well, but our assumption that this is directly related to settlement in the Chatham Islands could be wrong. Observed settlement at the Chatham Islands appears to be more episodic than at the main islands (authors' unpubl. data), and we suspect that since the islands present a small target, compared to the main islands, that pueruli may be less likely to navigate to them.

It is encouraging that there was less difference between simulations made with the model mean fields than between the models and CARS, because this suggests that the choice of diffusivity in model means is not that critical. However, we believe both model mean fields overestimate the strength of the East Cape Eddy and this is the main reason we had to use the CARS mean field model for settlement in CRAs 1 and 2 . This is not entirely satisfactory because quota management areas are interconnected and in principle one should use 
the same mean field for all quota management areas. Further development of the mean field from the regional hydro-dynamical model may solve this problem.

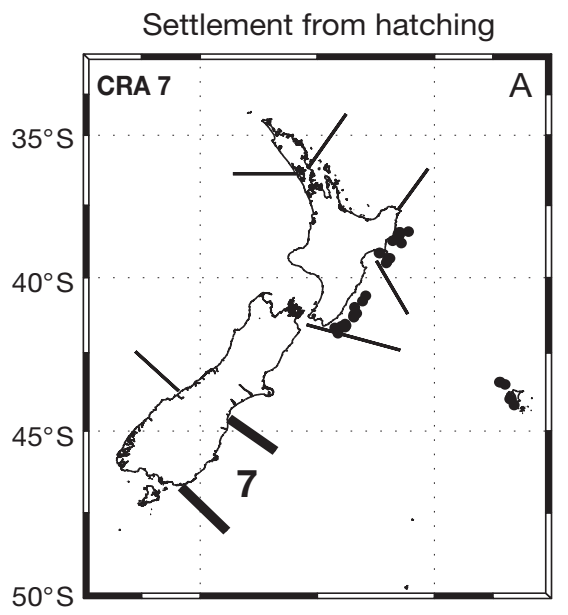

\section{Settlement of metamorphosis}
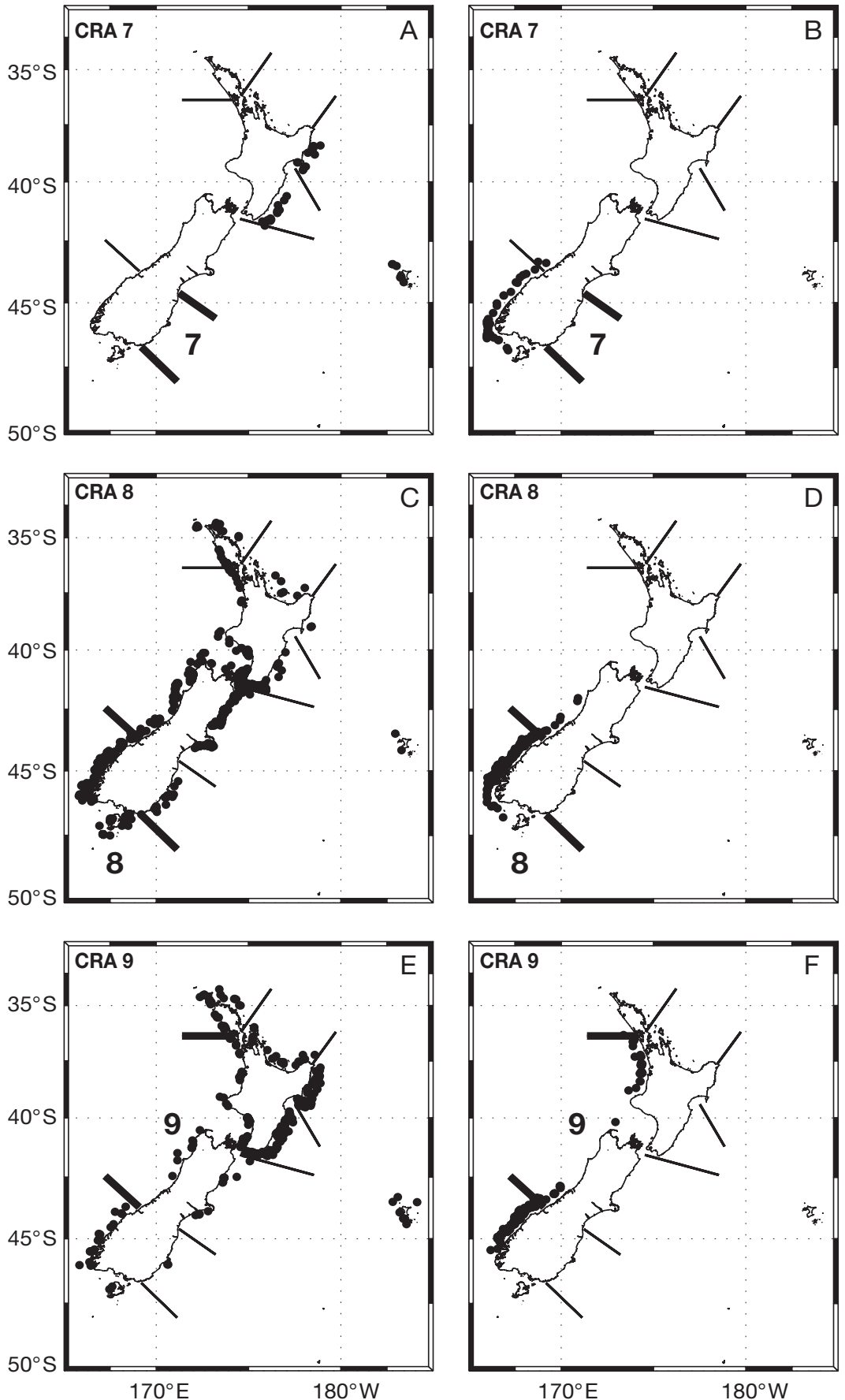
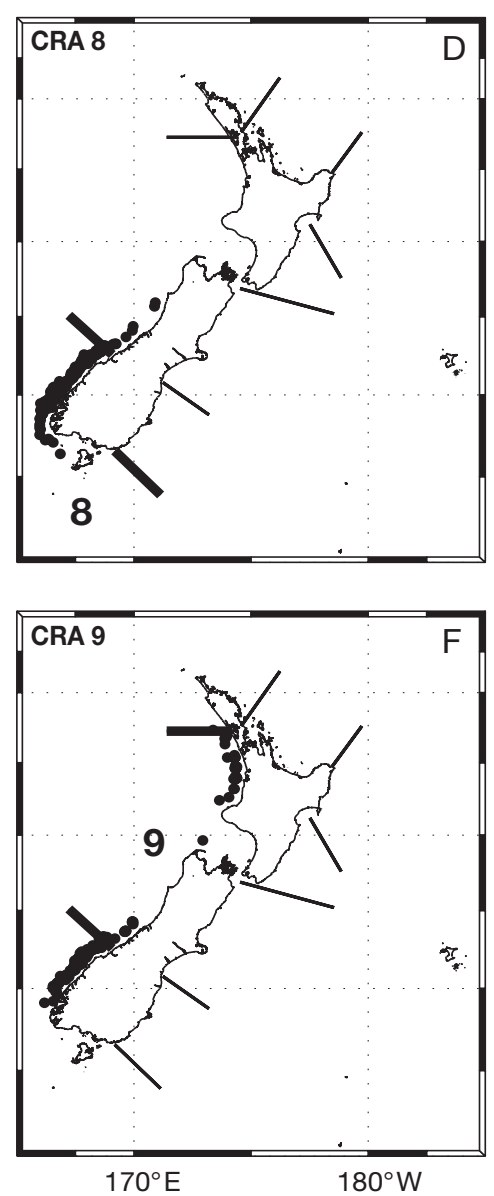

Fig. 14. Jasus edwardsii. Jasus edwardsii. (A,C,E) Successful settlement locations for phyllosomas hatched in denoted quota management area. $(B, D, F)$ Hatching locations for phyllosomas that successfully metamorphose in denoted quota management area. $(\mathrm{A}, \mathrm{B}) \mathrm{CRA} 7$; $(\mathrm{C}, \mathrm{D}) \mathrm{CRA} 8$; $(\mathrm{E}, \mathrm{F})$ CRA 9. Thick lines show limits for denoted CRA

\section{Insights into Jasus edwardsii biology}

Overall, our results are consistent with established ideas of Jasus edwardsii biology and life cycles. For example, the Wairarapa/East Cape eddy system is clearly the most important oceanographic feature in entraining lobster larvae off the southeast of the North Island. However, our model has also produced some findings that are new. In particular, the results indicate that adult populations from Fiordland to Stewart Island could be entirely maintained by local settlement; our best choice of parameters leads to settlement in CRA 8 that is only slightly lower than observed values. This does not mean that transport of phyllosomas from Australia does not happen (the presumed genetic homogeneity between Australia and New Zealand [Ovenden et al. 1992] and computed larval transport times [Chiswell et al. 2003] indicates that it does), but that such migration may not be necessary to support the Fiordland lobster stocks.

The model allows us to start to quantify the relative interdependencies of the quota management areas (Tables 2 \& 3). For example, while there is larval flow from South Island quota management areas to North Island quota management areas, there is very little larval flow from North Island quota management areas to their South Island counterparts. The results suggest that there are 4 major geographical areas in terms of larval dispersal.

- Far north, where CRA 1 receives the majority of its settlement from CRA 9. These are phyllosomas that are transported up the west coast of both islands. However, not many phyllosomas take this path-only $5 \%$ of the settlement originate from CRA 9, thus explaining the low settlement in our model

- East coast of the North Island (CRAs 2 to 4 ), where almost all the settlement originates from the east of the North Island, although there is a small contribution from the South Island quota management areas

- South Island fisheries (CRAs 5 and 7 to 9), where virtually all settlement is from CRA 8 
- Chatham Islands (CRA 6), which form a separate geographical area with a wide range of sources and destinations of settlement, but with the islands themselves being prominent in both

Our results were aggregated by quota management areas, but these areas may span natural divisions in the fate or source of phyllosomas. In particular, the break on the east coast probably occurs within CRA 5, rather than at the CRA 4/CRA 5 boundary.

How confident can we be of the results presented here? Clearly we can have more confidence about some than others. For example, we can be reasonably sure about the split between east coast North Island and South Island geographical areas. However, the low modelled settlement in CRAs 1 and 2 means that we must have lower confidence about the extent of the northern geographical zone.

This study has to be regarded as a first step in quantifying Jasus edwardsii larval dispersal around New Zealand. More accurate and higher-resolution numerical models of the oceanic currents will lead to some improvement in the estimation of the mean flow around New Zealand, and will allow investigation of the finer structure in the larval dispersal. For example, we may be able to investigate small-scale spatial differences in puerulus settlement. More and better data on egg production will improve the source terms used in the model, and better data on settlement will increase the confidence in the model validation.

However, perhaps the most important conclusion to be made from this study is that the results are relatively robust to differences in the physical model, but sensitive to metamorphosis algorithm parameters. Thus, understanding larval behaviour is the most critical aspect in determining larval connectivity. A better understanding of larval physiology is crucial in improving such studies of connectivity. This conclusion is certainly true for Jasus edwardsii and we suspect it is also true for most larval dispersal connectivity studies.

Acknowledgements. We thank Paul Breen for providing the biomass data that were used to determine the index of larval production. We also thank Matt Pinkerton for providing processed SeaWiFS data, and Graham Rickard for providing us with the numerical model mean fields. Andy McKenzie helped derive the settlement indices, for which we are grateful. Lew Incze and an anonymous reviewer provided reviews that greatly improved this paper. This work was supported by New Zealand's Ministry of Fisheries under project CRA2004/01, and by the Foundation of Research, Science and Technology, New Zealand, Contract CO1X0202.

\section{LITERATURE CITED}

Annala JH, Bycroft BL (1987) Fecundity of the New Zealand red rock lobster, Jasus edwardsii. NZ J Mar Freshw Res 21:591-597
Annala JH, Sullivan KJ, O'Brien CJ (2001) Report from the Mid-Year Fishery Assessment Plenary, November 2001: stock assessments and yield estimates. NIWA, Wellington

Bellen A, Zennaro M (2003) Numerical methods for delay differential equations. Oxford University Press, Oxford

Black KP (1994) Developments in our knowledge of dispersal on the Great Barrier Reef. In: Sammarco PW, Heron ML (eds) The bio-physics of marine larval dispersal. American Coastal and Estuarine Studies 45. Geophysical Union, Washington, DC, p 352

Blayo E, Mailly T, Barnier B, Brasseur P, LeProvost C, Molines JM, Verron J (1997) Complementarity of ERS 1 and TOPEX/POSEIDON altimeter data in estimating the ocean circulation: assimilation into a model of the North Atlantic. J Geophys Res 102:18573-18584

Booth JD (1994) Jasus edwardsii larval recruitment off the east coast of New Zealand. Crustaceana 66:295-317

Booth JD (2002) Early life history, recruitment processes and settlement of spiny lobsters. Fish Sci (Tokyo) 68:384-389

Booth JD, Phillips BF (1994) Early life history of spiny lobster. Crustaceana 66:271-294

Booth JD, Forman J, Stotter D, McKenzie A (2004) Settlement indices for 2002 for the red rock lobster (Jasus edwardsii). New Zealand Fisheries Assessment Report 2004/30. NIWA, Wellington

Bradbury IR, Snelgrove PV (2001) Contrasting larval transport in demersal fish and benthic invertebrates: the roles of behaviour and advective processes in determining spatial pattern. Can J Fish Aquat Sci 58:811-823

Bradford RW, Bruce BD, Chiswell SM, Booth JD, Jeffs A, Wotherspoon S (2005) The vertical distribution and diurnal migration patterns of Jasus edwardsii (Hutton, 1875) phyllosomas off the East Coast of the North Island, New Zealand. NZ J Mar Freshw Res 39:593-604

Chiswell SM (2000) The Wairarapa Coastal Current. NZ J Mar Freshw Res 34:303-315

Chiswell SM (2005) Mean and variability in the Wairarapa and Hikurangi Eddies. NZ J Mar Freshw Res 39:121-134

Chiswell SM, Booth JD (1999) Rock lobster Jasus edwardsii larval retention by the Wairarapa Eddy off New Zealand. Mar Ecol Prog Ser 183:227-240

Chiswell SM, Booth JD (2005) Distribution of mid- and latestage Jasus edwardsii phyllosomas: implications for larval recruitment processes. NZ J Mar Freshw Res 39: 1157-1170

Chiswell SM, Rickard GJ (2006) Comparison of model and observational ocean circulation climatologies for the New Zealand Region. J Geophys Res 111, doi:10.1029/ 2006JC003489

Chiswell SM, Roemmich D (1998) The East Cape Current and 2 eddies: a mechanism for larval retention? NZ J Mar Freshw Res 32:385-397

Chiswell SM, Wilkin J, Booth JD, Stanton B (2003) Trans Tasman Sea larval transport: Is Australia a source for New Zealand rock lobsters? Mar Ecol Prog Ser 247:173-182

Griffin DA, Wilkin JL, Chubb CF, Pearce AF, Caputi N (2001) Ocean currents and the larval phase of Australian western rock lobster, Panulirus cygnus. Mar Freshw Res 52: 1187-1199

Heath RA (1985) A review of the physical oceanography of the seas around New Zealand - 1982. NZ J Mar Freshw Res 19:79-124

Jeffs AG, Chiswell SM, Booth JD (2001) The distribution and condition of pueruli of the spiny lobster Jasus edwardsii offshore from north-east New Zealand. NZ J Mar Freshw Res 52:1211-1216 
Jeffs AG, Montgomery JC, Tindle CT (2005) How do spiny lobster post-larvae find the coast? NZ J Mar Freshw Res 39:605-618

Kanciruk P (1980) Ecology of juvenile and adult Palinuridae (spiny lobsters). In: Cobb JS, Phillips BF (eds) The biology and management of lobsters, Vol 2. Ecology and management. Academic Press, New York, p 59-96

Kittaka J, Ono K, Booth JD, Webber W (2005) Development of the red rock lobster, Jasus edwardsii, from egg to juvenile. NZ J Mar Freshw Res 39:263-277

Lesser JHR (1978) Phyllosoma larvae of Jasus edwardsii (Hutton) (Crustacea: Decapoda: Palinuridae) and their distribution off the east coast of the North Island, New Zealand. NZ J Mar Freshw Res 12:357-370

MacDiarmid AB (1989) Moulting and reproduction of the spiny lobster Jasus edwardsii (Decapoda: Palinuridae) in Northern New Zealand. Mar Biol 103:303-310

Mitchum GT (1994) Comparison of TOPEX sea surface heights and tide gauge sea levels. J Geophys Res 99: 24541-24553

Nishida S, Quigley BD, Booth JD, Nemoto T, Kittaka J (1990) Comparative morphology of the mouthparts and foregut of the final-stage phyllosoma, puerulus, and postpuerulus of

Editorial responsibility: Jon Hare, Narragansett, Rhode Island, USA the rock lobster Jasus edwardsii (Decapoda: Palinuridae). J Crustac Biol 10:293-305

Ovenden JR, Brasher DJ, White RWG (1992) Mitochondrial DNA analyses of the red rock lobster Jasus edwardsii supports an apparent absence of population subdivision throughout Australasia. Mar Biol 112:319-326

Phillips BF (1981) The circulation of the southeastern Indian Ocean and the planktonic life of the western rock lobster. Oceanogr Mar Biol Annu Rev 19:11-39

Phillips BF, Macmillan DL (1987) Antennal receptors in puerulus and postpuerulus stages of the rock lobster Panulirus cygnus (Decapoda: Palinuridae) and their potential role in puerulus navigation. J Crustac Biol 7:122-135

Rickard GJ, Hadfield MG, Roberts MJ (2005) Development of a regional ocean model for New Zealand. NZ J Mar Freshw Res 39:1171-1191

Ridgway KR, Dunn JR, Wilkin JL (2002) Ocean interpolation by 4-dimensional least squares - application to the waters around Australia. J Atmos Ocean Tech 19:1357-1375

Roemmich D, Sutton PJH (1998) The mean and variability of ocean circulation past northern New Zealand: determining the representativeness of hydrographic climatologies. J Geophys Res 103:13041-13054

Submitted: May 16, 2007; Accepted: August 13, 2007

Proofs received from author(s): January 24, 2008 